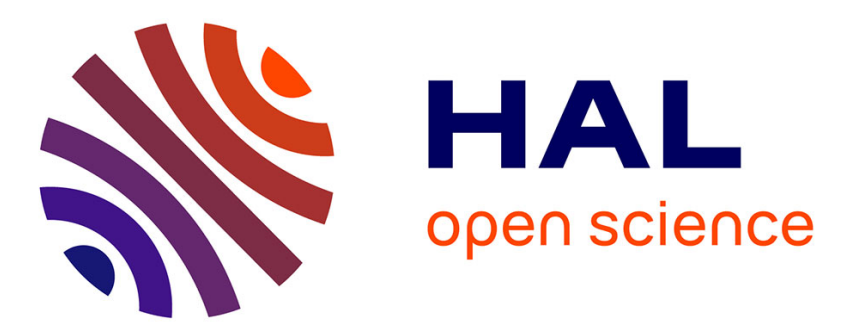

\title{
A flexible HCF modeling framework leading to a probabilistic multiaxial Kitagawa-Takahashi diagram
}

Daniel Bellett, Etienne Pessard, Franck Morel

\section{To cite this version:}

Daniel Bellett, Etienne Pessard, Franck Morel. A flexible HCF modeling framework leading to a probabilistic multiaxial Kitagawa-Takahashi diagram. International Fatigue Conference (11; Melbourne; 2014), Mar 2014, Melbourne, Australia. pp.1372-1378, 10.4028/www.scientific.net/AMR.891892.1372 . hal-01084221

\section{HAL Id: hal-01084221 \\ https://hal.science/hal-01084221}

Submitted on 18 Nov 2014

HAL is a multi-disciplinary open access archive for the deposit and dissemination of scientific research documents, whether they are published or not. The documents may come from teaching and research institutions in France or abroad, or from public or private research centers.
L'archive ouverte pluridisciplinaire HAL, est destinée au dépôt et à la diffusion de documents scientifiques de niveau recherche, publiés ou non, émanant des établissements d'enseignement et de recherche français ou étrangers, des laboratoires publics ou privés. 


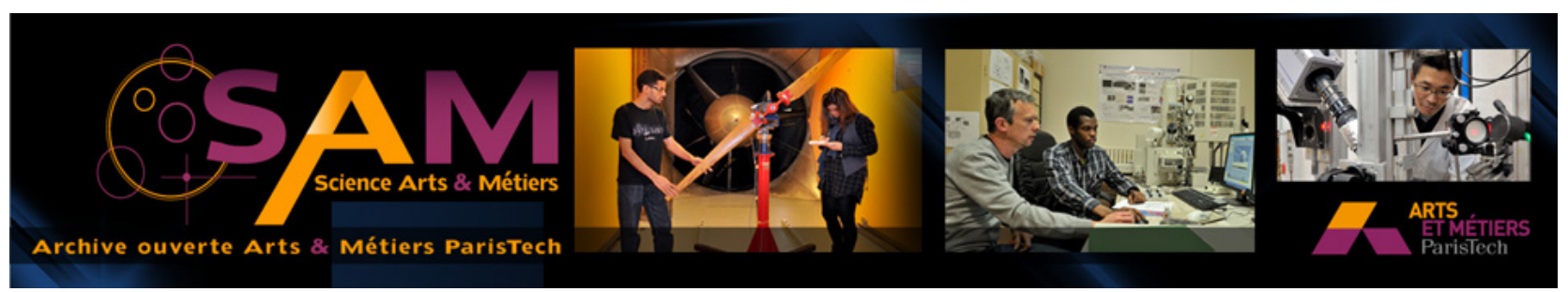

\section{Science Arts \& Métiers (SAM)}

is an open access repository that collects the work of Arts et Métiers ParisTech researchers and makes it freely available over the web where possible.

This is an author-deposited version published in: http://sam.ensam.eu

Handle ID: .http://hdl.handle.net/10985/8941

\section{To cite this version :}

Daniel BELLETT, Etienne PESSARD, Franck MOREL - A flexible HCF modeling framework leading to a probabilistic multiaxial Kitagawa-Takahashi diagram - In: International Fatigue Conference (11; Melbourne; 2014), Australia, 2014-03-03 - Fatigue 2014 : 11th International Fatigue Conference - 2014 


\title{
A flexible HCF modeling framework leading to a probabilistic multiaxial Kitagawa-Takahashi diagram
}

\author{
Daniel Bellett ${ }^{1, a^{*}}$, Etienne Pessard ${ }^{1, b}$ and Franck Morel ${ }^{1, c}$ \\ ${ }^{1}$ Laboratoire LAMPA, Arts et Métiers ParisTech, 2 Bd du Ronceray, 49035 Angers Cedex 01, \\ FRANCE \\ adaniel.bellett@ensam.eu, betienne.pessard@ensam.eu, cfranck.morel@ensam.eu \\ * Corresponding author
}

Keywords: high cycle fatigue, Kitagawa-Takahashi diagram, cast aluminum alloys, probability, defects.

\begin{abstract}
This article describes a flexible modeling framework which leads to the construction of a probabilistic, multiaxial Kitagawa-Takahashi diagram. This framework has been developed following experimental observations that clearly indicate that two independent fatigue damage mechanisms can be activated, at the same time, in metallic materials. Specifically, one damage mechanism is associated with crack initiation and the other with crack arrest. It is postulated that these damage mechanisms are more appropriately modeled using two different fatigue criteria or, more specifically, two completely different approaches to fatigue (i.e. a classical multiaxial fatigue criterion and a LEFM type criterion). Hence, the proposed modeling framework provides the possibility of combining any two suitable criteria, in a probabilistic framework based on the weakest link hypothesis and results in the continuous description of the Kitagawa diagram for any multiaxial stress state. It is shown that under certain conditions this approach is equivalent to the classical El Haddad approach to the short crack problem encountered in LEFM. However, the proposed framework is easily extended to multiaxial loading conditions. This modeling framework is demonstrated in detail via its application to multiaxial fatigue data for data taken from the literature.
\end{abstract}

\section{Introduction}

The Kitagawa-Takahashi diagram [1], shown schematically in Figure 1, is an extremely important contribution to the study of the high cycle fatigue behavior of metallic materials, as it represents many important concepts. In particular, the Kitagawa-Takahashi diagram:

a) highlights the difference in terms of the fatigue strength of cracked and non-cracked bodies.

b) defines the zone of validity for which Linear Elastic Fracture Mechanics (LEFM) predictions are applicable and allows the classification of cracks as being either long cracks or short cracks.

c) can be used to describe the dependence of the plain fatigue strength on the presence of defects (i.e. cast shrinkage pores, non-metallic inclusions, surface defects, etc.)

d) is generally accepted to represent two distinct fatigue damage mechanisms. That is, one mechanism associated with crack initiation and the other with crack propagation. It also defines the transition between these mechanisms.

The aim of this article is to present a flexible modeling framework in which two co-existing fatigue damage mechanisms can be simultaneously modeled using two different fatigue criteria. A weakest link probabilistic concept is subsequently used to combine the two models. This results in a probabilistic Kitagawa type diagram. This framework was first proposed by Pessard and Morel [2] for the prediction of anisotropic fatigue behavior of forged steels. The basic ingredients of this framework are:

1. The choice of two appropriate fatigue criteria to model the two damage mechanisms.

2. The threshold quantities of both criteria are defined in terms of Weibull distributions. This allows the experimentally observed scatter to be taken into account and associates a probability of failure with each criterion (and damage mechanism). 
3. The weakest link hypothesis is then used to determine the total probability of failure due to both damage mechanisms. This leads to a continuous transition between the predictions from the two criteria.

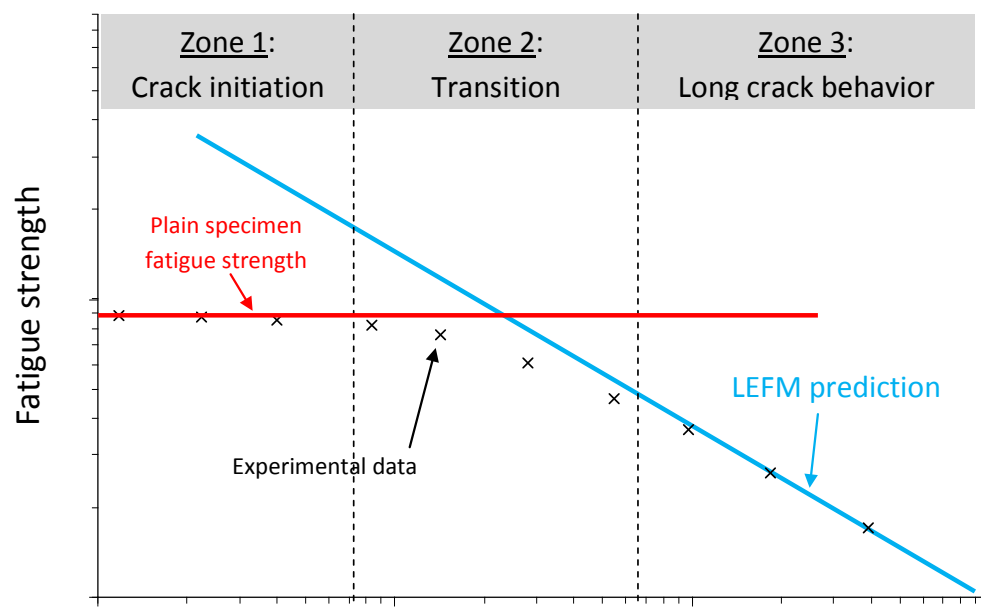

Crack size, a

Figure 1 : A schematic representation of the Kitagawa-Takahashi diagram

\section{Description of the probabilistic modeling framework}

It is important to realize that any two appropriate fatigue criteria can be used within this framework. It is sufficient to define one criterion to describe the crack initiation damage mechanism (mechanism 1) and another for the crack propagation mechanism (mechanism 2).

Modeling of mechanism 1. This section is devoted to the modeling of the crack initiation damage mechanism (mechanism 1). Many modeling approaches have been proposed to determine the possibility of crack initiation. Table 1 summarizes several high cycle fatigue criteria that can be used in the proposed framework.

As a general rule most fatigue criteria can be defined by an equivalent mechanical quantity (i.e. stress, strain, energy, etc.), which is compared to a threshold quantity, for a given number of cycles. Crack initiation is subsequently predicted if the equivalent quantity is greater than or equal to the threshold quantity (see Eq. (1)). In the following, for convenience, these will be referred to stress quantities. Hence, the condition for crack initiation is defined by: $\sigma_{e q} \geq \sigma_{t h}$

In order to take into account the inherent stochastic nature of the fatigue phenomenon it is proposed, as part of the modeling framework, to use a two parameter Weibull distribution [3][4] to describe the threshold stress. In this work the Weibull distribution is used because it is easily applicable to the weakest link theory. This choice then makes it possible to define the probability of crack initiation within a grain. Eq. (2) shows the probability density function used to define the threshold stress.

$$
f_{01}\left(\sigma_{t h}\right)=\frac{m_{1}}{\sigma_{t h 01}}\left(\frac{\sigma_{t h}}{\sigma_{t h 01}}\right)^{m_{1}-1} \exp \left(\frac{\sigma_{t h}}{\sigma_{t h 01}}\right)^{m_{1}}
$$

where $\sigma_{t h 01}$ is the scale parameter and $\mathrm{m}_{1}$ is the shape parameter (or the Weibull exponent) used to reflect the scatter associated with the threshold stress and by consequence the scatter associated with the fatigue damage mechanism. The probability of microcrack initiation in a grain corresponds to the probability of finding a grain with a threshold stress $\sigma_{t h}$ that is less than the applied equivalent stress $\sigma_{e q}$. This can be expressed as:

$$
\begin{aligned}
& P_{F 01}\left(\sigma_{t h}<\sigma_{e q}\right)=\int_{0}^{\sigma_{e q}} f_{01}\left(\sigma_{t h}\right) d \sigma_{t h} \\
& P_{F 01}=1-\exp \left[-\left(\frac{\sigma_{e q}}{\sigma_{t h 01}}\right)^{\mathrm{m}_{1}}\right]
\end{aligned}
$$


Table 1 : Stress amplitude criterion and three well known fatigue criteria divided into equivalent and threshold parts

\begin{tabular}{|l|c|c|}
\hline Criterion & Equivalent quantity, $\sigma_{e q}$ & Threshold quantity, $\sigma_{t h}$ \\
\hline Stress amplitude & $\sigma_{I, a}$ & $s_{-1}$ \\
\hline Fatemi-socie [5] & $\Delta \gamma\left(1+k_{F S} \frac{\sigma_{n, \max }}{\sigma_{y}}\right)$ & $\beta_{F S}$ \\
\hline Crossland [6] & $\sqrt{J_{2, a}}+k \sigma_{H, \max }$ & $\lambda$ \\
\hline Dang Van [7][8] & $\max _{\vec{n}}\left[\max _{\mathrm{t}}\left[\tau_{\text {meso }}+\alpha_{D V} \sigma_{H}\right]\right]$ & $\beta_{D V}$ \\
\hline
\end{tabular}

In order to obtain the probability of crack initiation for the complete structure $P_{F 1}$, the weakest link theory is used [9]. The probability of survival of the structure $\left(1-P_{F 1}\right)$ is defined as the product of the survival probabilities of each elementary volume or surface. In this work it will be assumed that crack initiation is essentially a surface phenomenon, where the quantity $S_{01}$ corresponds to the surface area of an individual surface grain and $S_{\Omega 1}$ is the total surface area of a specimen. Hence the probability of survival of the complete structure is given by:

$$
1-P_{F 1}=\prod_{S_{\Omega 1}}\left(1-P_{F 01}(M)\right)
$$

This then implies that:

$$
P_{F 1}=1-\exp \left[-\frac{1}{S_{01}} \int_{S_{\Omega 1}}\left(\frac{\sigma_{e q}}{\sigma_{t h 01}}\right)^{m_{1}} d S\right]
$$

For a uniform surface stress, this expression can be simplified to:

$$
P_{F 1}=1-\exp \left[-\frac{S_{\Omega 1}}{S_{01}}\left(\frac{\sigma_{e q}}{\sigma_{t h 01}}\right)^{m_{1}}\right]
$$

Modeling of mechanism 2. The second fatigue damage mechanism is associated with the nonpropagation (or the arrest) of long cracks. The classical LEFM approach will be used to demonstrate the modeling framework. Although, it should be kept in mind that the framework is not limited to LEFM. Any criterion that predicts the fatigue behavior of long cracks or defects could be used (e.g. Elastic-Plastic Fracture Mechanics or the Murakami criterion [10]). When using the classical LEFM approach it is assumed that crack propagation does not occur if the condition $\Delta \mathrm{K}<\Delta K_{t h}$ is satisfied. By using a second Weibull distribution to define the scatter associated with the crack propagation threshold $\Delta K_{t h}$ and by following the same procedure as outlined above, the probability of failure probability, for an entire uniformly loaded specimen, associated with damage mechanism 2 is given by:

$$
P_{F 2}=1-\exp \left[-\frac{s_{\Omega 2}}{S_{02}}\left(\frac{\Delta K}{\Delta K_{t h 02}}\right)^{m_{2}}\right]
$$

Combining the two damage mechanisms. Finally, the survival probability of an entire component, due to both damage mechanisms, is equal to the product of the two survival probabilities. Essentially, the weakest link hypothesis is employed once again. This assumes that the two damage mechanisms are independent.

$$
1-P_{F}=\left(1-P_{F 1}\right)\left(1-P_{F 2}\right)
$$

For a uniform surface stress, the total probability of failure can be written as:

$$
P_{F}=1-\exp \left\{-\left[\frac{S_{\Omega 1}}{S_{01}}\left(\frac{\sigma_{e q}}{\sigma_{t h 01}}\right)^{m_{1}}+\frac{S_{\Omega 2}}{S_{02}}\left(\frac{\Delta K}{\Delta K_{t h 02}}\right)^{m_{2}}\right]\right\}
$$

This is simply a bimodal Weibull distrubution. As can be seen in Eq. 10 the scale effect is explicitly taken into account via the terms $\frac{S_{\Omega 1}}{S_{01}}$ and $\frac{S_{\Omega 2}}{S_{02}}$. However, in the following, for reasons of simplicity, the scale effect will be neglected, which corresponds to the assumption that the results 
presented below are for specimens with approximately the same surface area. Eq. 10 can therefore be simplified to:

$$
P_{F}=1-\exp \left\{-\left[\left(\frac{\sigma_{e q}}{\sigma_{t h 01}^{\prime}}\right)^{m_{1}}+\left(\frac{\Delta K}{\Delta K_{t h 02}^{\prime}}\right)^{m_{2}}\right]\right\}
$$

where $\sigma_{t h 01}^{\prime}=\sigma_{t h 01}\left(\frac{S_{01}}{S_{\Omega 1}}\right)^{1 / m_{1}}$ and $\Delta K_{t h 02}^{\prime}=\Delta K_{t h 02}\left(\frac{S_{02}}{S_{\Omega 2}}\right)^{1 / m_{2}}$

Uniaxial loads and the original Kitagawa-Takahashi diagram. When considering uniaxial tensile loads, the original Kitagawa-Takahashi diagram can be reproduced by the proposed framework, if the (a) simple stress amplitude criterion and (b) the LEFM criterion are used. This criteria combination is described by the following equations:

$$
\sigma_{e q}=\sigma_{1, a} \geq s_{-1} \quad \text { and } \quad \Delta K=Y 2 \sigma_{1, a} \sqrt{\pi a} \geq \Delta K_{\mathrm{th}}
$$

where $\mathrm{Y}$ is the crack shape correction factor. If for the sake of simplicity it is assumed that $\mathrm{m}_{1}=\mathrm{m}_{1}=\mathrm{m}$. By substituting Eq. 12 into Eq. 11 the following expression for the fatigue

$$
\sigma_{1, a}\left(P_{F}, a\right)=\left[\frac{\ln \left(\frac{1}{1-P_{F}}\right)}{\left(\frac{1}{\sigma_{t h 01}^{\prime}}\right)^{m}+\left(\frac{Y 2 \sqrt{\pi a}}{\Delta K_{t h 02}^{\prime}}\right)^{m}}\right]^{\frac{1}{m}}
$$
strength as a function of the probability of failure, and the crack length, can be established:

One of the original solutions to the LEFM short crack problem was proposed by El Haddad [11], who introduced the material constant, $\mathrm{a}_{0}$, to describe the Kitagawa-Takahashi diagram. It can be demonstrated mathematically that the El Haddad approach is a specific case of the proposed probabilistic modeling framework, defined by Eq. 13. The El Haddad equation corresponds to a Weibull exponent of $\mathrm{m}=2$ and a failure probability of $P_{F}=0.544$.

$$
2 \sigma_{1, a}(0.544, a)=\frac{\ln \left(\frac{1}{1-0.544}\right)}{Y \sqrt{\frac{a+a_{o}}{\Delta K_{t h 02}^{\prime}}}}=\frac{\Delta K_{t h}}{Y \sqrt{\pi\left(a+a_{o}\right)}} \quad \text { where } \quad a_{o}=\frac{1}{\pi}\left(\frac{\Delta K_{t h}}{2 s_{-1}}\right)^{2}
$$

Extension to multiaxial loads. In order to apply the proposed modeling framework to multiaxial loading conditions, two criteria combinations are investigated: "Crossland \& LEFM" and "Crossland and Murakami". Table 2 summarizes the application of the proposed modeling framework for three different loading conditions: (a) fully reversed uniaxial push-pull loads, (b) fully reversed torsion, and (c) combined in-phase synchronous tension-torsion with $\tau / \sigma=1$.

Application to multiaxial experimental data for the C35. In the following, two criteria combinations, summarized in Table 2, are applied to experimental data taken from the literature for the C35 steel. This material is a ferrito-pearlitic, low alloy steel containing $0.35 \%$ carbon and has been the subject of many fatigue investigations in the literature [12], [13], [14], [15], [16].

Table 3 summarizes the fatigue data used for this material [12]. Data for both plain specimens (defect size $=0 \mu m$ ) and specimens containing artificial hemispherical surface defects of various sizes are considered for three different loading conditions. The data in bold is used to identify the parameters of the proposed modeling framework.

Table 2: Fatigue strength at $1 \times 10^{7}$ cyc for C35 steel [12]

\begin{tabular}{|c|c|c|c|}
\hline $\begin{array}{c}\text { Defect } \\
\text { size } \\
(\mu \mathrm{m})\end{array}$ & $\begin{array}{c}\text { Tensile } \\
S_{-1} \\
(\mathrm{MPa})\end{array}$ & $\begin{array}{c}\text { Torsion } \\
t_{-1} \\
(M P a)\end{array}$ & $\begin{array}{c}\text { Tension- } \\
\text { torsion } \\
s t_{-1}(M P a)\end{array}$ \\
\hline 0 & $\mathbf{2 3 0}$ & $\mathbf{1 4 0}$ & 185 \\
\hline 90 & 200 & 140 & 175 \\
\hline 500 & $\mathbf{1 5 0}$ & 120 & - \\
\hline
\end{tabular}

Greater information concerning the identification procedure can be found in reference [17].

Figure 2 shows the predictions of the proposed modeling framework using the equations for the "Crossland \& LEFM" criteria combination. The experimental data listed in Table 2 is also shown. It can be seen that in the short crack zone of the diagram the Crossland criterion faithfully predicts the 
results for the combined tension-torsion loading condition. However, in the long crack domain, it appears that the LEFM criterion overestimates the fatigue strength. This difference may be due to the fact that the experimental results are for artificial surface defects with a hemispherical shape, and the LEFM criterion makes the assumption that these defects are equivalent to cracks.

Table 3 : Application for the proposed modeling framework, using the "Crossland \& LEFM" criteria combination and the "Crossland \& Murakami” criteria combination, for three different loading conditions

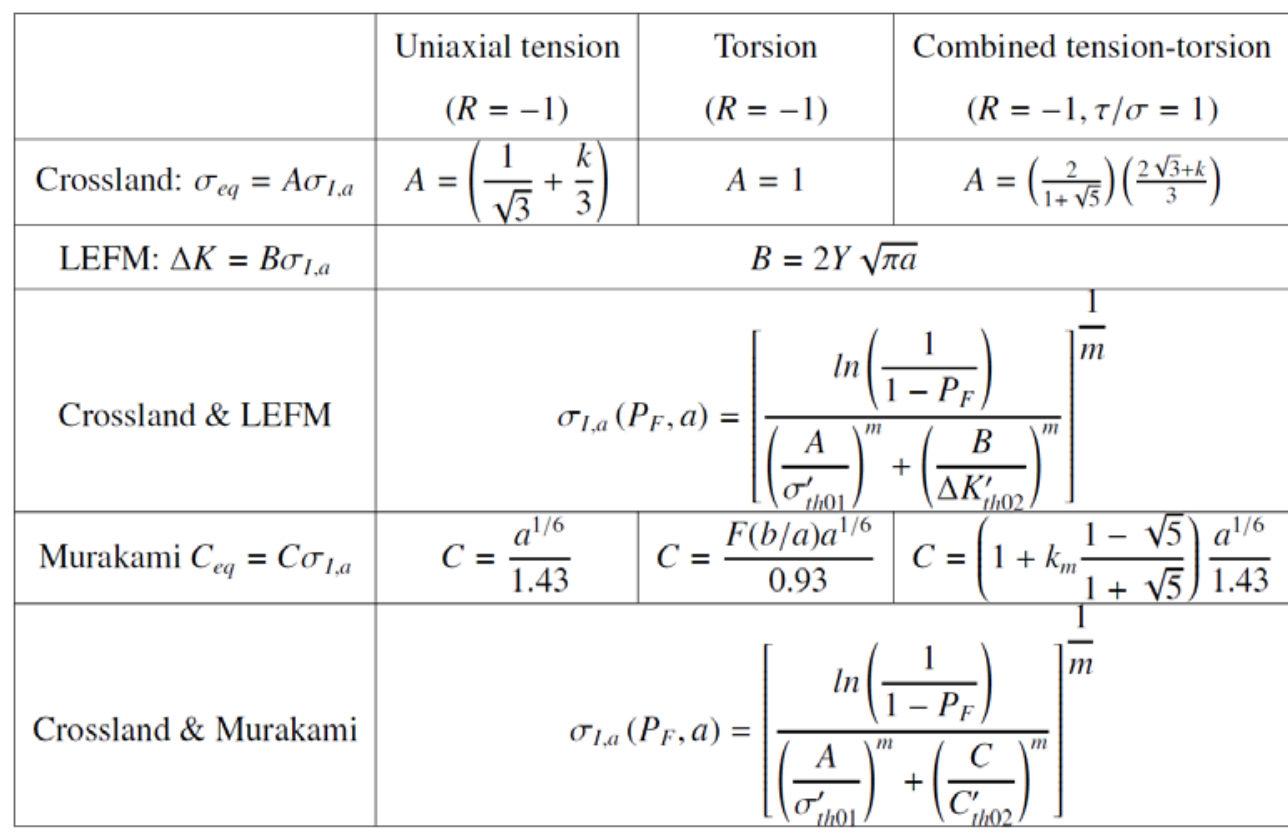

Figure 3 shows the predictions obtained with the proposed modeling framework, using the "Crossland \& Murakami” criteria combination. It can be seen that the predictions, for all three loading conditions, are in very good agreement with the experimental data. The Murakami criterion uses the $\sqrt{\text { area }}$ parameter (where area is the projected area of a defect on a plane perpendicular to the direction of the maximum principal stress) and the hardness to define the fatigue strength. For multiaxial loads, the extension to the Murakami criterion proposed by Endo and Ishimoto [18] is used.

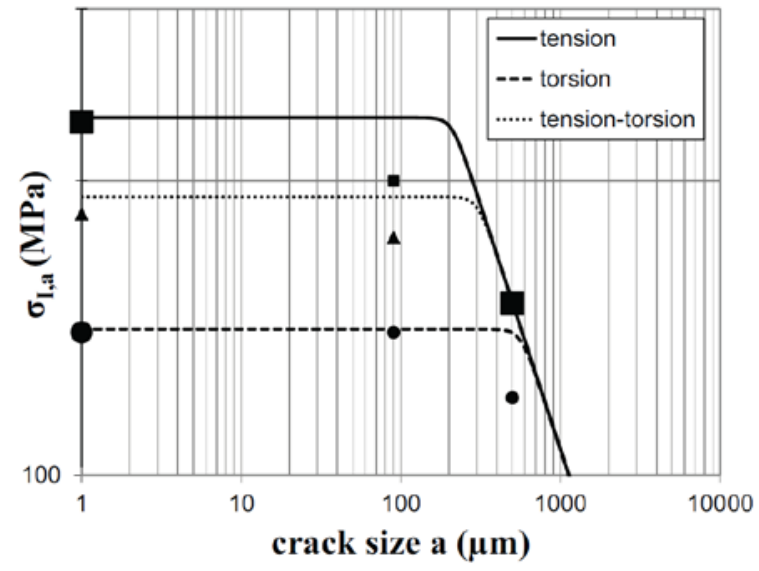

Figure 2 : Multiaxial Kitagawa-Takahashi type diagram established using the Crossland \& LEFM criteria combination, for the C35 steel $\left(\mathrm{P}_{\mathrm{F}}=0.5\right)$. The large data points are used for the identification of the model

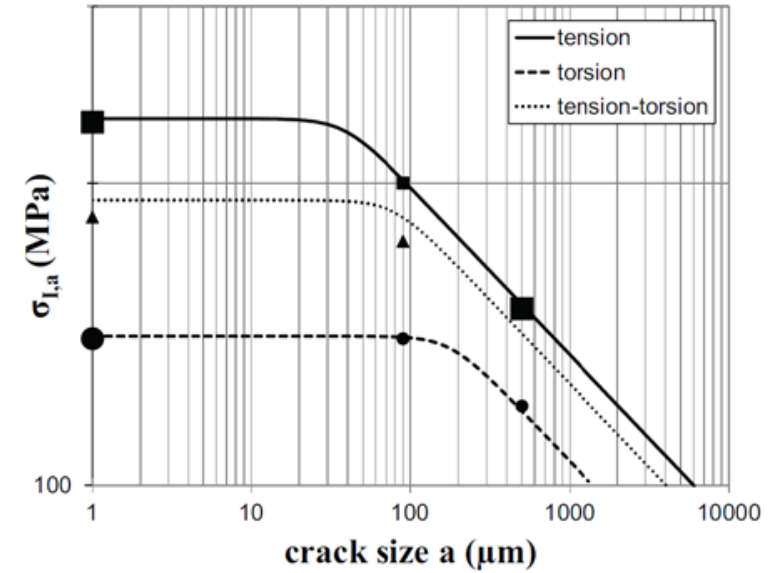

Figure 3 : Multiaxial Kitagawa-Takahashi type diagram established using the Crossland \& Murakami criteria combination, for the C35 steel $\left(\mathrm{P}_{\mathrm{F}}=0.5\right)$. The large data points are used for the identification of the model

\section{Conclusion}

The principal conclusions of this work can be summarized as follows:

- The proposed modeling framework is a flexible way of taking into account two coexisting fatigue damage mechanisms via the combination of two appropriate high cycle fatigue criteria. 
One criterion to model crack initiation damage and a second for crack propagation (or crack arrest).

- The proposed modeling framework can be used to establish probabilistic Kitagawa-Takahashi type diagrams that have a mechanistic basis and are able to realistically reflect the experimentally observed scatter associated with the damage mechanisms.

- The proposed modeling framework makes it possible to generate probabilistic KitagawaTakahashi type diagrams for multiaxial loading conditions, if appropriate multiaxial criteria are used.

- When the classical LEFM criterion is used in this framework the short crack problem is circumvented or avoided. It is assumed that short cracks fall into the transition region of the Kitagawa-Takahashi diagram.

\section{References}

[1] H. Kitagawa, S. Takahashi, Applicability of fracture mechanics to very small cracks. In: ASM Proceedings of 2nd international conference on mechanical behaviour of materials, Metalspark, Ohio, (1976), pp. 62731

[2] E. Pessard, F. Morel, A. Morel, The anisotropic fatigue behavior of forged steel, Adv Engng Mater (2009), 11, pp.732-5

[3] W. Weibull, A statistical theory of the strength of materials, Roy Swed Inst Engng Res Report (1939), 151

[4] W. Weibull, A statistical distribution function of wide applicability, ASME J Appl Mech (1951), 18, pp.293-7

[5] A. Fatemi, D.F. Socie, Critical plane approach to multiaxial fatigue damage including out-ofphase loading. Fatigue Fract Engng Mater Struct (1988), 11-3, pp. 149-65

[6] B. Crossland, Effect of large hydrostatic pressures on the torsional fatigue strength of an alloy steel. In: Int conf on fatigue of metals, London (1956)

[7] K. Dang Van, Sur la résistance á la fatigue des métau,. Sci Tech Armement, (1973) 47

[8] E. Charkaluk, A. Constantinescu, H. Matournam, K. Dang Van, Revisiting the Dang Van criterion. Proc Engng, (2009), 1-1, pp. 143-6

[9] A.M. Freudenthal, In: H. Liebowitz, editor. Fracture, vol. 2, New York: Academic Press, (1968), pp. 591-619

[10]Y. Murakami, Metal fatigue: effects of small defects and non-metallic inclusion, London, Elsevier, (2002)

[11] M.H. El Haddad, T.H. Topper, K.N. Smith, Prediction of non propagating cracks, Engng Fract Mech, (1979), 11, pp.573-84

[12]A.J. McEvily, M. Endo, S. Ishihara, The influence of biaxial stress on the fatigue behaviour of defect-containing steels. ICF1, (2005)

[13]T. Billaudeau, Y. Nadot, G. Bezine, Multiaxial fatigue limit for defective materials: mechanisms and experiments, Acta Materialia, (2004), vol 52, pp. 3911-3920

[14] Y. Nadot, T. Billaudeau, Multiaxial fatigue limit criterion for defective materials, Engineering Fracture Mechanics, (2006), vol. 73-1, pp. 112-133

[15]L. Flaceliere, F. Morel, A. Dragon, Competition between mesoplasticity and damage under HCF Elasticity/damage shakedown concept, Int J Fatigue, (2007), vol. 29, pp. 2281-2297

[16]F. Morel and N. Huyen, Plasticity and damage heterogeneity in fatigue, Theoretical and Applied Fracture Mechanics, (2008), vol. 49-1, pp. 98-127

[17]E. Pessard, D. Bellett, F. Morel, I. Koutiri, A mechanistic approach to the Kitagawa-Takahashi diagram using a multiaxial probabilistic framework, Eng Fract Mech, 109, (2013), pp. 89-104

[18] M. Endo, I. Ishimoto, The fatigue strength of steels containing small holes under out-of-phase combined loading, Int J Fatigue, (2006), 28, pp. 592-7 